BONAFIDE: Jurnal Teologi dan Pendidikan Kristen

\title{
TINJAUAN BUKU
}

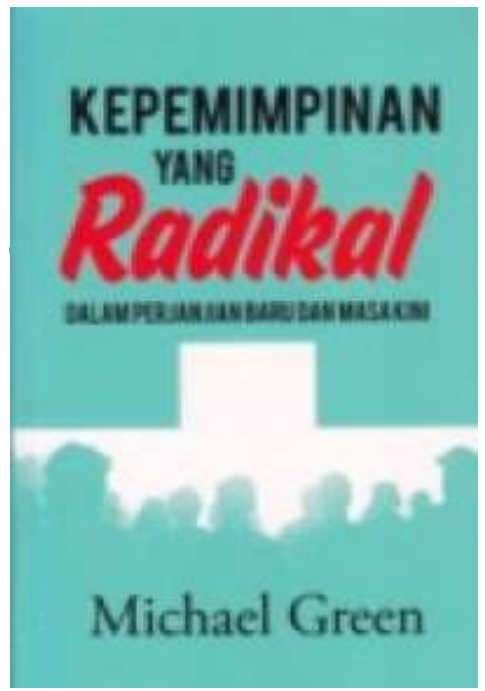

Judul

: Kepemimpinan Yang Radikal

Dalam Perjanjian Baru dan Masa

\section{Kini}

Penulis : Michael Green

Terbit $\quad: 2019$

Halaman : 134

ISBN $\quad$ : 978-623-90566-4-3

Penerbit $\quad$ : STT Cipanas dan Indonesia Cahaya

Rahmat Empati

\section{Jansakti Saddu Saly}

Sekolah Tinggi Teologi Arastamar Merauke salyjansaktisaddu@gmail.com

Secara umum Edward Michael Bankes Green mendalami apologetika dan evangelism berbasis teks-teks Perjanjian Baru. Michael Green (selanjutnya, MG) mempunyai juga minat menulis tentang Kkristen mula-mula sebagai pembuka terhadap pemahaman Kristen masa kini dalam hal penginjilan, apologetika, kristologi, kepemimpinan dan bagaimana kekristenan membawa injil dalam dunia pluralis. MG merasakan perlunya sikap dan pola yang harus dijalani orang Kristen dalam kehidupan yang beragam (karena tidak lagi bisa dihindari) dan kian hari kian kompleks (Band. Hutahaean 2020b, 259). Bukunya berjudul "Who Is This Jesus?" (thn 2007) disebut-sebut sebagai buku yang klasik nan kontemporer.

Buku ini menyinggung segmen tersendiri yakni kepemimpinan. Persis seperti judulnya, MG menjabarkannya dari sosok Yesus, para murid dan orang yang dekat 
BONAFIDE: Jurnal Teologi dan Pendidikan Kristen

www.jurnal.sttissiau.ac.id/Volume 1/Nomor 2/Desember 2020/hal.293-298

dengan Yesus. Dari eksposisi tiga tokoh tersebut buku ini memberikan insight berarti bagi pembaca baik para gembala jemaat, pemimpin perusahaan Kristen dan pemimpin lain di luar ke dua bidang itu. Contohnya di Bab VII, MG memberikan pemahaman baru terhadap pembaca tentang feminisme Alkitab yang dinyatakan sebagai suatu kesempatan bagi perempuan untuk melayani sama dengan kaum pria (Green 2019, 89). Tokoh-tokoh perempuan di PL dan di teks-teks pada PB seperti Febe (Rom.16), Maria, Trifena, Trifosa dan Persis semuanya mendapat pujian justeru oleh karena kiprah pelayanannya. Sekitar sepuluh tahun sebelumnya, adalah seorang Dana Heller Levitt yang menyuarakan hal serupa terkait tantangan tersendiri terhadap kepemimpinan perempuan (Levitt 2011). Kepemimpinan di bawah perempuan memiliki kualitas tidak kalah dibanding kepemimpinan pria.

Kepemimpinan menyangkut kepada banyak kalangan dari berbagai suku, ras, dan agama tentu menjadi pengalaman dan tantangan tersendiri bagi pemimpin Kristen. Hidup damai dan rukun dengan pemeluk agama lain dapat terwujud dengan pola tepat. Hutahaean juga memberi wawasan berarti dalam hal ini dengan memahami ajaran agama masing-masing dengan benar (Hutahaean 2020b). Baik MG dan Hutahaean sepakat bahwa pemahaman agama yang benar dan Alkitabiah memiliki kontribusi yang besar bagi perwujudan hubungan yang harmonis di tengah masyarakat yang majemuk tak terkecuali dalam bidang kepemimpinan.

Di bagian awal buku ini MG memberi delapan alasan mengapa Yesus dapat disebut memberi teladan yang baik sebagai model pemimpin. Tiga di antaranya patut dicatat yakni karena keteladanan Yesus bersifat magnetis (Green 2019). Bagi MG orang-orang di era Yesus melihat keteladanan-Nya dengan melakukan ajaran- 
BONAFIDE: Jurnal Teologi dan Pendidikan Kristen

www.jurnal.sttissiau.ac.id/Volume 1/Nomor 2/Desember 2020/hal.293-298

Nya seturut Kitab Suci. Performa Yesus yang demikian menimbulkan rasa hormat dan karakter yang kuat di mata masyarakat. Alasan berikutnya adalah karena dalam kepemimpinan-Nya, tidak abai dalam memperlengkapi serta menyanggupkan para pengikut. Yesus tidak hanya menuntut kompentensi, tim kerja, kejujuran, inovasi seturut tuntuntan zaman, namun seiring dengan itu memberikan coaching agar murid-murid-Nya mampu menemukan dan menggunakan karunia-karunia yang ada pada mereka.

Yang terakhir dari delapan tersebut yakni Yesus taat kepada Kitab Suci. MG melihat Yesus tidak terlalu terikat dengan tradisi yang ada dalam diri-Nya sebagai orang Yahudi. Seringkali landasan ide, argumentasi Yesus berdasarkan penggunaan kata- 'ada tertulis.' Inilah mengapa Yesus menjadikan ungkapanungkapan dalam Kitab Suci sangat dijunjung tinggi, melampaui kebajikan, hikmat, dan tradisi yang dikenal pada masa itu.

Petrus menjadi murid Yesus yang dituliskan dalam menyingkap kepemimpinan yang radikal. MG tidak memungkiri banyak hal dalam diri Petrus seperti impulsive, nyaris kasar (dalam hubungannya dengan murid-murid Yesus), atau pernah tiga kali menyangkal sebagai pengikut Yesus. Sebaliknya tiga puluh tahun setelah kematian Yesus, Injil tersebar luas di Roma (Hutahaean 2017). Tujuh aspek dalam diri Petrus sangat jelas dan mudah dipahami dalam paparan MG, di mana dua di antaranya yakni 'hubungan antar staf' dan kemampuan melewati 'masa sulit' (Green 2019). Dengan menyebut dirinya sebagai 'teman Penatua' (Surat 1 Petrus), setidaknya sebagai trigger untuk menumbuhkan semangat tim dan membangkitkan loyalitas sehingga tim bersedia untuk melakukan apa saja bagi 
BONAFIDE: Jurnal Teologi dan Pendidikan Kristen

www.jurnal.sttissiau.ac.id/Volume 1/Nomor 2/Desember 2020/hal.293-298

Petrus. Pasande juga menjelaskan pentingnya kerjasama tim untuk capaian yang maksimal. Bisa dilakukan dengan memberi pengaruh, membimbing atau memberi inspirasi (Pasande 2020, 63). Di bagian lain, masa sulit pernah dihadapi Petrus dan murid-murid Yesus. Petrus tidak menghindari kesulitan, tapi dengan sikap 'berjagajaga' terus berupaya melewatinya.

Orang yang dekat dengan Yesus dalam paparan MG adalah Lukas, penulis Injil Lukas, dan Kisah Para Rasul. MG menguraikan enam prinsip kepemimpinan yang didapat dari Lukas sebagai seorang sosok dan kedua tulisannya di PB. Dua di antaranya: Pertama, bagi Lukas, kepemimpinan adalah anugerah Tuhan. Untuk pelayanan di segmen gereja dan luar gereja, seorang pemimpin membutuhkan karisma ilahi (sebagai prasyarat). Kepemimpinan dalam gereja misalnya oleh presbiter berasal dari otorisasi Allah, yakni fasilitasi yang diberikan langsung olehNya secara pribadi dan berbeda-beda bagi tiap orang. Dari tulisan Lukas di Kisah Para Rasul peran presbiter (penatua) dipahami sebagai 'pengawas jalannya hukum' (Green 2019). Semua pekerjaan yang ada dalam pundak presbiter (penatua) tidak dapat diperhitungkan sebagai pelayanannya jika tanpa dipenuhi oleh Roh Kudus (KPR.6:5-6). Dalam perannya di gereja, Hutahaean menyatakan lebih tegas bahwa peran penatua tidak kalah pentingnya dengan pendeta, diaken, juga jabatan struktural bishop, ketua sinode atau pemimpin organisasi keagamaan lainnya seperti PGI, dlsb. Penatua justeru bagai engsel di antara pendeta dan jemaat untuk satu sidang jemaat yang bertumbuh (Hutahaean 2020a, 21).

MG menulis buku ini dengan gaya bahasa popular namun dasar eksegesis teks Alkitab sangat baik. Ketika memberikan penjelasan model kepemimpinan Paulus 
BONAFIDE: Jurnal Teologi dan Pendidikan Kristen

www.jurnal.sttissiau.ac.id/Volume 1/Nomor 2/Desember 2020/hal.293-298

dari surat-surat yang ditulisnya, MG hati-hati dalam memberi arti kata yang dipakai dalam suratnya itu. Seperti makna kata 'proistamenoi' dalam (1Tes.5:12 dan Rom.12:8) untuk makna asalnya. Gagasan dan ide yang diusung dalam buku ini tajam, menjadi kebutuhan masa kini meski berdasar dari pengalaman penulis sekitar 75 tahun lalu. Pada bagian pendahuluan tampak kesan bagi pembaca bahwa MG tidak ingin melukai perasaan para pendeta Anglikan ketika menyatakan bahwa kebanyakan dari mereka abai terhadap prinsip kepemimpinan yang akan diuraikan dalam buku tersebut. Cukup menarik untuk dibaca.

Untuk pembaca dari kalangan mahasiswa Teologi dan kalangan pendeta senior, buku ini masih sangat diperlukan guna memberi khazanah yang segar dalam bidang kepemimpinan. MG memberi kejelasan perlunya leadership mind dalam diri pemimpin gereja, agar tidak melulu tentang eksegese teks, hubungan konteks dengan tujuan kepenulisan Kitab akhirnya abai dalam kepedulian pada bidang kepemimpinan. Membenamkan diri dalam usaha memahami Kitab Suci tidak bisa menjadi pilihan terhadap bidang menjadi pemimpin yang radikal dan biblikal di gereja serta masyarakat. Kedua bidang ini bukan pilihan atau opsional tetapi dualitas yang tidak terpisahkan. Dengan begitu pembaca dari kalangan mahasiswa teologi atau para pendeta tidak menjadi penjaga gereja yang hanya memastikan gereja berjalan sebagaimana mestinya (Green 2019), namun menjadikan diri bagai kutub magnetik sehingga banyak orang kian mengenal Kristus dan mendekat padaNya. Mereka dapat menjadi pemimpin untuk kemuliaan-Nya dan demi kemurahanNya. 
BONAFIDE: Jurnal Teologi dan Pendidikan Kristen

\section{DAFTAR PUSTAKA}

Green, Michael. 2019. Kepemimpinan Yang Radikal Dalam Perjanjian Baru dan Masa Kini. Cipanas: STT Cipanas dan Indonesia Cahaya Rahmat Empati.

Hutahaean, Hasahatan. 2017. "Pengantar Memahami Surat Roma Dengan Baca Gali Alkitab." Cultivation 1 (2): 216-30.

2020a. Pelayan Tuhan di Gereja dan Masyarakat. Luwuk: Pustaka Star's Lub.

- 2020b. "Tantangan Teologi Agama-agama: Suatu Diskursus Model." KURIOS (Jurnal Teologi dan Pendidikan Agama Kristen) 6 (2): 255-70. https://doi.org/https://doi.org/10.30995/kur.v6i2.136.

Levitt, Dana Heller. 2011. "Women and leadership: A developmental paradox?" Adultspan Journal 9 (2): 66-75. https://doi.org/10.1002/j.21610029.2010.tb00072.x.

Pasande, Purnama. 2020. Pemimpin dan Kepemimpinan Kristen; Memahami Substansi Kepemimpinan Kristen. Luwuk: Pustaka Star's Lub. https://doi.org/10.31219/osf.io/czydf. 